\title{
Elementos de uma História de Formação Docente: as memórias de um professor de Matemática
}

\author{
Elements of a Teachers' Education History: the memories of a Mathematics \\ teacher
}

Maria Laura Magalhães Gomes*

\begin{abstract}
Resumo
Este artigo contempla o livro de memórias de Carlos Galante (1920-2003), professor de Matemática e autor de livros didáticos do estado de São Paulo, que lecionou em diversas instituições públicas e particulares brasileiras por quase 50 anos. $\mathrm{O}$ texto principia com considerações de natureza teórico-metodológica acerca dos relatos autobiográficos como fonte de pesquisa. Em seguida, apresentam-se Carlos Galante e suas memórias, que são analisadas segundo três aspectos: formação familiar e escolar inicial do autor, sua vida como estudante do Ginásio do Estado e do curso de Matemática da USP e sua atuação como professor de Matemática. Nos comentários finais, as memórias de Galante são relacionadas a dimensões teórico-metodológicas que orientam a pesquisa com fontes autobiográficas.
\end{abstract}

Palavras-chave: Escrita Memorialística. Carlos Galante. História da Formação de Professores de Matemática no Brasil.

\begin{abstract}
This article focuses on the book of memories of Carlos Galante (1920-2003), professor of Mathematics and author of textbooks from the state of São Paulo, who taught in several Brazilian public and private institutions for almost 50 years. The text begins with theoretical-methodological considerations about autobiographical reports as a source of research. Next, Carlos Galante and his book are presented. The memories are analyzed according to three aspects: the author's initial family and school formation, his life as a student and his role as a Mathematics teacher. In the final comments, Galante's memories are related to theoretical-methodological dimensions that guide the research with autobiographical sources.
\end{abstract}

Keywords: Memorial Writing. Carlos Galante. History of Mathematics Teachers’ Education in Brazil.

\section{Introdução}

Escritos literários e autobiográficos vêm sendo concebidos como fontes relevantes no campo da História Cultural, o que tem conduzido uma série de investigações em História da Educação, nas últimas décadas, a se dedicarem a explorá-las, particularmente no Brasil. Muitos trabalhos resultam de análises diversificadas dessas fontes para compreender

\footnotetext{
* Doutora em Educação (UNICAMP). Professora titular do Departamento de Matemática e do Programa de Pósgraduação em Educação (UFMG), Belo Horizonte/MG, Brasil. Bolsista de Produtividade do CNPq. Endereço para correspondência: Av. Antônio Carlos, n. 6627, Cidade Universitária - Pampulha, Belo Horizonte/MG, Brasil, CEP 31270-901. E-mail: mlauramgomes@gmail.com.
} 
diferentes dimensões da educação no país. É o caso, por exemplo, de Galvão (1998), Lacerda (2003), Zilberman (2004), Sousa (2005), Bastos (2006), Peres e Borges (2015), Neves e Galvão (2016). Especificamente no campo da História da Educação Matemática, que entendemos, conforme Miguel (2014, p. 29), como resultado de uma aproximação dialógica específica entre História, Educação e Matemática que focaliza "todas as práticas educativas mobilizadoras de cultura matemática em quaisquer contextos de atividade humana, dentre eles, sobretudo, os contextos educativos escolares", as fontes literárias e/ou autobiográficas também têm sido contempladas. Nessa linha, inserem-se trabalhos como Gomes $(2008,2016)$, Búrigo (2015) e Brito e Gonçalves (2015). Merecem ser citadas, ainda, no que concerne ao tema da história da formação de professores de Matemática ou que ensinam Matemática, pesquisas que se valem da História Oral $^{1}$. Trata-se de produções que contemplam experiências, principalmente escolares, relacionadas a processos de ensino e aprendizagem de conhecimentos matemáticos.

Esse movimento é parte integrante da História Cultural, no qual assumem especial importância relatos narrativos, estruturados "em torno a uma trama argumentativa em que uma sequência temporal, personagem(ns) e uma situação fazem com que os enunciados tenham sentido próprio no contexto do argumento" (GARNICA, 2015, p. 182-183). Pesavento (2012, p. 57) comenta a relevância adquirida pelas sensibilidades - "as formas pelas quais indivíduos e grupos se dão a perceber, comparecendo como um reduto de tradução da realidade por meio das emoções e dos sentidos". Nesse cenário, cresce a consideração a vestígios do passado aos quais pouca atenção tinha sido dada anteriormente pelos pesquisadores e tem se configurado uma valorização particular do indivíduo, da subjetividade, das histórias de vida. As narrativas autobiográficas ou a chamada escrita de si, na forma de textos redigidos na primeira pessoa do singular ou de depoimentos orais transcritos e/ou textualizados, tornam-se documentos apreciados pelo seu potencial para a compreensão do pretérito.

De acordo com Viñao (2004), tem sido ampliado o espaço da subjetividade na História da Educação, cujas pesquisas mais atuais têm dado atenção ao currículo vivido, às práticas e culturas escolares, às reformas educativas em sua aplicação prática e à profissão e às práticas docentes. Nessa perspectiva, cresceu o interesse pelos documentos autobiográficos de diversos tipos, estando entre eles os livros de memórias.

\footnotetext{
${ }^{1}$ Notadamente aquelas desenvolvidas pelo Grupo de História Oral e Educação Matemática (Ghoem). Veja-se, por exemplo, Garnica (2014).
} 
O foco do presente texto é o livro Memórias, de um professor de Matemática paulista, Carlos Galante (1920-2003), que traz como subtítulo "Professor e Engenheiro, Como perder o medo da Matemática" (GALANTE, 1997). Antes de abordar a obra, tecemos algumas considerações relativas ao uso de fontes autorreferenciais.

\section{Relatos autobiográficos como fonte de pesquisa: aspectos teórico-metodológicos}

Viñao (2004) é um dos autores que, avaliando os escritos autobiográficos como férteis para a investigação em história, promove uma discussão sobre cuidados a serem observados no uso dessas fontes. Por exemplo, ele chama a atenção para uma característica que não é exclusiva desses textos: eles são narrados seletivamente de forma a constituir relatos de uma vida que pode "ser mais ou menos incoerente ou azarenta, mas que, em todo caso, é um contínuo" (p. 355). O autor pondera que qualquer documento histórico é um fragmento ou um vestígio e "todo texto seleciona e cria uma nova continuidade textual - aparência de continuidade - que substitui a continuidade real, mas silencia boa parte dela" (Idem). Bourdieu (2006), ao refletir sobre a "ilusão biográfica”, afirma:

Sem dúvida, cabe supor que o relato autobiográfico se baseia sempre, ou pelo menos em parte, na preocupação de dar sentido, de tornar razoável, de extrair uma lógica ao mesmo tempo retrospectiva e prospectiva, uma consistência e uma constância, estabelecendo relações inteligíveis, como a do efeito à causa eficiente ou final, entre os estados sucessivos, assim constituídos em etapas de um desenvolvimento necessário (BOURDIEU, 2006, p. 184).

O sociólogo assinala, então, a propensão do autor do relato autobiográfico a converterse em "ideólogo de sua própria vida" (BOURDIEU, 2006, p. XX), elegendo, a partir de um intuito global, alguns acontecimentos significativos, estabelecendo conexões entre eles para lhes conferir coerência.

Em consequência da busca desse efeito por parte dos autobiógrafos, o pesquisador precisará estar atento às possibilidades e dificuldades dos textos, "qual é sua estrutura e disposição, observando quais são os critérios de seleção utilizados pelo autor, o que foi silenciado e por que, quais foram seus propósitos ao escrever o respectivo texto, e de que fala ou a que se refere no mesmo" (VIÑAO, 2004, p. 356).

Em outro trabalho (VIÑAO, 2000), o pesquisador espanhol alerta para as diferenças de estilo entre os autores, que podem escrever de maneira simples ou afetada, limitar-se às descrições, atingir ou não a beleza literária. Cabe ao pesquisador dessas fontes, então, captar essas características para a melhor compreensão do texto ou de seu escritor. Uma recomendação primordial é que o intérprete se informe sobre contextos, acontecimentos e 
pessoas mencionadas nas obras. Soma-se a ela a necessidade de buscar conhecer as intenções ou propósitos motivadores da escrita das memórias. Ainda segundo Viñao (2004), tais intenções ou propósitos associam-se a tipos diferentes de autobiografias. Há as intimistas, justificativas, vingativas, e também aquelas que são o simples resultado de um desejo ou necessidade pessoal de escrever da parte do autor. Ademais, existem memórias que, por iniciativa própria ou alheia, foram escritas expressamente visando à publicação, e há memórias redigidas apenas para a pessoa que as escreve ou destinadas a um círculo restrito de leitores.

Incluem-se, entre os cuidados aconselhados por Viñao (2004), o de recorrer também a outras fontes. Não se trata de fazer isso em busca da verdade: como Gomes (2004), acreditamos que nenhum tipo de documento retrata por si só o que "verdadeiramente" se passou. Uma narrativa relata o que ocorreu no passado, mas não é a única possibilidade de se fazer isso, já que o acontecido pode ser narrado em múltiplas versões. Entretanto, se a opção pelo uso de escritos autobiográficos se caracteriza pela valorização da subjetividade, é preciso acentuar que narrativas autobiográficas não nos relatam "o que houve", mas aquilo que, num tempo posterior ao narrado, o autor diz que vivenciou. A impressão de veracidade que essas narrativas oferecem requer a conscientização do pesquisador e a adoção de uma postura crítica em relação aos testemunhos, não para duvidar do que eles dizem, mas para não apreendê-los como expressão do que realmente aconteceu, do mesmo modo como se recomenda que se proceda quanto a outros documentos.

Outro aspecto importante é ressaltado por pesquisadores como Larrosa (2004), que sublinha a existência de instâncias e relações de poder que repercutem na forma, nos contextos e nos fins relativos à composição das narrativas, o que torna imprescindível considerar os lugares sociais e institucionais em que os relatos autorreferenciais são produzidos, reproduzidos, mediados, avaliados e utilizados.

Finalizando estas breves considerações teórico-metodológicas, é essencial salientar a dimensão subjetiva, parcial e situada de qualquer escuta ou leitura das narrativas autobiográficas. A recepção de um texto está ligada à capacidade de acolhimento do leitor, definida simultaneamente por abertura e limitações em relação a um horizonte de mundo, como diz Ricoeur (2010). As vivências e escolhas socioculturais de cada pesquisador repercutem, sem dúvida, nas interpretações de um mesmo escrito e, assim, a escolha de narrativas autobiográficas e seu uso em uma investigação diferirão de leitor para leitor, segundo as particularidades de cada um. 


\section{Carlos Galante e suas memórias}

Nascido no bairro do Brás, em São Paulo, no dia 27 de fevereiro de 1920, Carlos Galante diplomou-se no curso de Matemática da Universidade de São Paulo (USP) em 1944, e também em Engenharia, pela Escola Nacional de Engenharia, do Rio de Janeiro, em 1949. Lecionou Matemática por quase cinquenta anos, em diversas instituições públicas e particulares, nos níveis secundário e superior, tendo, inclusive, ministrado aulas no curso de normalistas. Participou da fundação de muitas escolas de nível médio e universitário no estado de São Paulo. Dentre elas, merece destaque a Faculdade de Filosofia, Ciências e Letras de Santo André, onde foi um dos responsáveis pela estruturação inicial do curso de Matemática. Exerceu a engenharia na Prefeitura de Santo André, tendo atuado no Departamento de Águas e Esgotos. Ocupou também outros cargos na administração municipal daquela cidade, como os de secretário de Obras e diretor do Departamento de Educação. Galante projetou-se, ainda, no cenário nacional, como autor de uma coleção de livros didáticos de Matemática destinados ao curso ginasial, publicados pela Editora do Brasil, a partir de 1949, que tiveram um grande número de edições².

Martins-Salandim (2012), em sua pesquisa sobre os cursos de Matemática fundados no estado de São Paulo nas décadas de 1960 e 1970, entrevistou o professor Dirceu Douglas Salvetti, no ano de 2009, sobre o curso da Faculdade de Filosofia, Ciências e Letras de Santo André, estabelecido em 1966. Salvetti enfatizou o protagonismo de Carlos Galante na criação desse curso e acentuou que "na época, a proposta do curso era uma revolução, era um curso de Matemática voltado para a indústria, que incluía computação e tudo o mais” (MARTINSSALANDIM, 2012, p. 133). Outro dos colaboradores da mesma pesquisa, o professor Alésio João de Caroli, chamou a atenção para os livros didáticos do professor Galante:

O Galante tinha um livro de Matemática para o Ginásio, junto com o Osvaldo Marcondes dos Santos, era da Editora do Brasil. Foi anterior aos livros do Oswaldo Sangiorgi. O Sangiorgi ficou famoso depois e teve o Scipione também. Antes do Galante, que eu me lembre, havia livros de Matemática para o Colégio e para o Ginásio

\footnotetext{
${ }^{2}$ Trata-se da coleção Matemática, em quatro volumes, publicada por Galante, em algumas versões em coautoria com Osvaldo Marcondes dos Santos. Uma rápida pesquisa em livrarias virtuais mostrou a presença de vários desses volumes, em edições das décadas de 1950 e 1960. Pelo Banco de Dados Livres, da USP, constatamos que em 1965 o livro da $1^{a}$ série estava em sua $51^{a}$ edição e o da $3^{\text {a }}$ série na $26^{a}$ edição. O próprio Galante afirma (1997, p. 119) que o primeiro volume da coleção alcançou mais de cem edições. Essas obras foram, sem dúvida, sucessos editoriais no mercado brasileiro de livros didáticos. Braghini (2012) investigou a Editora do Brasil no mercado de didáticos nos anos 1960 e 1970, estudando o sucesso da empresa à luz das relações de seus diretores com os grupos civis e militares então no poder. A pesquisadora assinala que a editora, alinhada ao regime militar vigente na época, beneficiou-se das políticas governamentais, particularmente a partir de seus investimentos na disciplina Educação Moral e Cívica.
} 
de autores cariocas como o Mello e Souza, que é o Malba Tahan... (MARTINS-SALANDIM, 2012, p. 134).

De Caroli assinalou que, embora fruto de um trabalho coletivo, o curso de Matemática de Santo André é devedor especial do memorialista: "quem teve muita influência nesse curso foi o Galante, foi o pioneiro, foi quem criou o curso, quem convidou o pessoal, colegas e os levou para lá" (Idem, p. 134). De acordo com De Caroli, Galante foi professor de Programação de Computadores e seu papel foi fundamental quanto ao caráter totalmente inovador do curso de Santo André, que incorporou o computador ao Ensino Superior de Matemática ainda na década de 1960. O problema de adquirir um computador, difícil de ser resolvido devido aos altos custos, foi solucionado por Carlos Galante, que, como engenheiro da prefeitura da cidade, solicitou a compra pela administração municipal, para instalação na Fundação que mantinha o curso. Em troca, essa Fundação usaria o computador no atendimento das demandas da prefeitura (MARTINS-SALANDIM, 2012, p. 138).

Jornais da década de 1960 noticiaram o vínculo entre a administração municipal de Santo André e o referido curso de Matemática, salientando o pioneirismo do uso do computador para emitir guias para a cobrança de taxas diversas e tratar de aspectos referentes à gestão dos funcionários municipais. Uma matéria do Jornal do Brasil $^{3}$ de domingo e segunda-feira, respectivamente 28 e 29 de maio de 1967, traz palavras de Carlos Galante como diretor do Centro de Processamento de Dados da Prefeitura Municipal, a ser inaugurado no dia 31 do mesmo mês. Segundo Galante (1997), o uso da computação eletrônica iria assinalar "uma nova era na administração municipal", que deixaria "de ser dirigida de maneira empírica" (p. 94). Menos de mês depois, a edição de 18 (domingo) e 19 (segundafeira) de junho de 1967 veiculava mais notícias a respeito do papel do computador marca Burroughs, série 300/500, na cobrança de tributos municipais imobiliários em Santo André. Essa segunda matéria enumerava as vantagens da computação eletrônica na tarefa e apresentava, mais uma vez, declarações de Carlos Galante, agora explicitando a conexão entre a aquisição do computador pela Prefeitura e as necessidades do curso de Matemática da Faculdade de Filosofia da Fundação Santo André.

Revela o engenheiro Carlos Galante que com a instalação, em março do ano passado, do curso de Matemática da Faculdade de Filosofia, Ciências e Letras da Fundação Santo André, com a finalidade de preparar professores para o ensino médico (sic) e formar matemáticos para a indústria - "surgiu a

\footnotetext{
3 O Jornal do Brasil está disponível na Hemeroteca Digital da Biblioteca Nacional. Disponível em: <http://memoria.bn.br/DocReader/docreader.aspx?bib=030015 08\&pasta=ano\%20196\&pesq=carlos\%20gala nte>. Acesso em: 7 jun. 2017.
} 
necessidade de se dotar a referida seção de um computador eletrônico, o responsável pela revolução industrial da segunda metade do nosso século".

- Naquela ocasião - continua - a Faculdade de Filosofia da Fundação, com o seu Centro de Processamento de Dados já em funcionamento, assumiu o compromisso de implantar na Prefeitura de Santo André a computação eletrônica, trabalho iniciado pelo lançamento de tributos imobiliários (JORNAL DO BRASIL, 18 e 19 de junho de 1967, p. 102).

Mais de um ano depois, em 20 de agosto de 1968, outro jornal do Rio de Janeiro, o Diário de Notícias ${ }^{4}$, divulgava informações detalhadas sobre a Faculdade de Filosofia de Santo André, referindo-se a suas instalações e aos cursos oferecidos, entre eles o de Matemática Industrial. A matéria enfatizava o pioneirismo desse curso, de "dupla finalidade: preparar professores para o ensino e formar matemáticos para trabalharem nas indústrias" (p. 13). Segundo o jornal, o currículo era comum aos dois objetivos, devendo o estudante escolher uma ou outra carreira no último ano, no qual as questões sobre o ensino seriam enfatizadas para os optantes pelo magistério e seria oferecido "um programa muito específico" (1968, p. 13) para aqueles que escolhessem a modalidade direcionada para as ações na indústria. A reportagem destaca, ainda, a presença do computador do Centro de Processamento de Dados, cujo diretor, Carlos Galante, acentuava a extrema necessidade do equipamento para a formação de matemáticos para a indústria.

O livro de memórias de Carlos Galante foi publicado pela mesma editora dos livros didáticos do autor, a Editora do Brasil, em 1997. Composta por um prefácio do próprio autor e 22 capítulos, fartamente ilustrada por fotografias e imagens variadas, que incluem cartas, bilhetes, versos, convites e recortes de jornais de escolas em que o autor estudou ou trabalhou, a obra mostra que seu autor guardou-se "em papel”, conforme sublinha Cunha (2008). A autora comenta o hábito de guardar papéis - no caso de Galante são fotos, cartas, jornais escolares, convites de formatura e outros eventos -, com a intenção de proteger-se do esquecimento, evitando que se perdesse "o que pela passagem do tempo, deveria ser consumido, esquecido, destruído, virado lixo” (p. 112). São papéis reunidos em função das diversas atividades do autor, que constituem um arquivo "composto por documentos produzidos em função de necessidades cotidianas e afazeres habituais" (idem), que registra e espelha a história de quem o reuniu.

Galante conta muitos episódios de sua vida e, ainda que narrem cenas de seu ambiente familiar e estudantil e registrem lembranças sobre pais, irmãos e infância no bairro do Brás, as memórias incidem predominantemente em sua diversificada atuação profissional como

\footnotetext{
4 O Diário de Notícias está disponível na Hemeroteca Digital da Biblioteca Nacional. Disponível em: <http://memoria.bn.br/DocReader/DocReader.aspx?bib=093718 04\&pesq=carlos\%20galante\&pasta=ano\%2019 6ㄱ. Acesso em: 7 jun. 2017.
} 
professor e engenheiro. Por entendermos a formação docente como um processo contínuo que vai além da realização de um curso que habilita para o exercício do magistério, abarcando a vida pessoal, a preparação acadêmica inicial e o trajeto profissional dos professores, vamosexplorar algumas partes do livro de Carlos Galante para abordar aspectos da formação familiar e escolar do autor, seus professores, sua formação no curso de licenciatura em Matemática da USP, bem como características das concepções de ensino de Matemática evidenciadas na narração de suas práticas como docente.

As memórias do autor dedicam extenso espaço a relatos sobre muitas outras atividades que exerceu - engenheiro, ocupante de cargos importantes na administração municipal de Santo André, candidato a prefeito daquela cidade, perito avaliador de empréstimos e patrimônios a serviço do Banco do Brasil e da Justiça do Trabalho, jurado na Comarca de Santo André, coordenador do Projeto Rondon para o Grande ABC, fundador de instituições diversas. Embora constituam parte indispensável da trajetória pessoal e profissional de Carlos Galante, não os contemplamos em nosso trabalho. Privilegiamos os aspectos mencionados anteriormente porque são eles os elementos que consideramos fundamentais na formação de um professor de Matemática.

\section{Formação familiar e escolar nas memórias de Carlos Galante}

No Prefácio de seu livro de memórias, Carlos Galante salienta que sua vida não é "extraordinária", mas teve "seus lances interessantes", principalmente em razão de sua origem simples, "o que exigiu muito esforço e dedicação para a conquista dos patamares alcançados" (GALANTE, 1997, p. 9).

"O Brás que conheci” é o título do primeiro capítulo, dedicado a sua infância e família. O autor retrata seus pais, imigrantes italianos que chegaram ao Brasil em torno de 1900 e se estabeleceram naquele bairro de São Paulo, onde criaram seus filhos. O pai de Galante era um comerciante de laticínios adquiridos em Minas, que viajava frequentemente para o interior no exercício de sua atividade. No sobrado em que o autor nasceu, o andar inferior era ocupado pela casa comercial do chefe da família, falecido precocemente, aos 44 anos, quando Carlos, o caçula de seis irmãos, tinha apenas cinco anos. Da mãe, Galante ressalta a grande dedicação ao lar, ilustrando-a com o relato de que era tudo "feito em casa: o pão, o sabão, a lingüiça e o macarrão" (GALANTE, 1997, p. 11). A mãe não tinha nem auxiliares domésticas nem aparelhos que facilitassem suas tarefas, e trabalhava do início do 
dia até tarde da noite. Após a morte do pai, os irmãos mais velhos de Galante transformaram sua loja num estabelecimento de "secos e molhados", conforme a linguagem da época.

Galante faz uma descrição bastante minuciosa do Brás, com menções à geografia do bairro e a seus meios de transporte, com destaque para o bonde, bem como às lojas, aos cinemas, teatros e restaurantes. Estando próximo dos 80 anos quando escreveu seu livro, o memorialista ainda guardava os nomes desses estabelecimentos, assim como os dos moradores da região.

Percebe-se que o autor procurou registrar de maneira viva os costumes do bairro em que foi criado, comparando-os aos do momento em que escrevia. Ademais, Carlos Galante explicita o orgulho compartilhado pelos que viveram no Brás, sublinhando que "não obstante fosse um bairro de gente humilde, de lá saíram nomes ilustres em vários ramos de atividade" (GALANTE, 1997, p. 15) e fundamentando sua afirmativa com uma lista de professores, cientistas, engenheiros, médicos e autoridades políticas que viveram no Brás.

Nas memórias, há somente uma referência aos estudos primários do autor: aos sete anos, dois anos depois que seu pai faleceu, ele iniciou o primeiro ano do Grupo Escolar, e ia à escola vestido todo de preto por sua mãe, porque, na época, o luto era conservado rigorosamente por muito tempo. Galante ressalta a situação econômica desfavorável de sua família, em virtude da morte do pai, e comenta que não teria conseguido cursar o Ensino Superior sem o incentivo do doutor Fausto Macedo, proprietário de um "Curso de Admissão ao Ginásio do Estado" (GALANTE, 1997, p. 17) nas proximidades da residência da família. Nesse contexto, o autor acentua que em sua família "mal se sabia da existência de um ginásio" (p. 17), já que seu irmão mais velho, que havia cursado a Escola de Comércio, como era comum entre as famílias italianas do Brás, estava sempre viajando a trabalho e sua mãe, além de viver dificuldades financeiras, não poderia orientá-lo, “pois, apesar de inteligente, nunca havia frequentado uma escola" 5 " (Idem). Galante considera que era uma pretensão muito grande a de ingressar no Ginásio do Estado, na época a única escola secundária oficial gratuita da cidade de São Paulo, devido às dificuldades das provas aplicadas por professores "considerados verdadeiros carrascos" e ao número enorme de candidatos por vaga, mais de vinte (Ibidem). Todo esse relato se localiza no capítulo "Aluno do Velho e Tradicional Ginásio do Estado".

\footnotetext{
${ }^{5} \mathrm{O}$ memorialista conta que sua mãe lhe dizia que, na aldeia na Itália de onde viera, as mulheres não podiam ir à escola, porque os pais eram os responsáveis pelos arranjos de casamento e procuravam impedir que suas filhas aprendessem a escrever para evitar que enviassem bilhetes para os rapazes.
} 
Carlos conseguiu ser aprovado "com muito esforço e um pouco de sorte" (p. 17) e ingressou no ginásio em 1933. Ele enfatiza que foi colocado numa turma, o $1^{\circ}$ Ano $\mathrm{B}$, na qual não estavam os que haviam obtido as melhores notas nas provas de acesso. Porém, o autor foi reprovado nesse primeiro ano e avalia, ao recordar, que suas muitas dificuldades advieram da falta de orientação por parte de sua família. A partir da repetição do $1^{\circ}$ ano, Galante não registra outros problemas graves nos estudos e narra ter terminado o ginásio em 1938. Parecenos importante a reflexão do autor ao ponderar sobre seu próprio desempenho, justificando-o pelas circunstâncias de não ser somente um estudante e ter precisado contribuir para o orçamento familiar: "Nunca passei de um aluno médio, pois, além de estudar, trabalhava na casa comercial de meus irmãos" (Idem).

As lembranças quanto aos livros usados na época no Ginásio do Estado ressaltam a origem francesa dessas obras e salientam a quase inexistência de obras didáticas brasileiras na década de 1930. Outro aspecto destacado é a dificuldade de aquisição de livros. Galante os comprava na Livraria Francesa, sediada na Praça da Sé. Valorizando o ato de aquisição de um livro, chega a dizer que essa situação, para os estudantes, era como ganhar "uma joia preciosa" (p. 18). A carência de livros era suprida, em parte, por idas à biblioteca da escola ou à municipal.

Galante narra que conservou um recorte do Diário Oficial do Estado, de dezembro de 1938, no qual são informados os resultados dos alunos de sua escola por ordem de classificação na turma, e comenta que no último ano sua média foi 56, abaixo da média 62 obtida pelos primeiros lugares.

\section{No Ginásio do Estado e no curso de Matemática da USP}

As lembranças de Carlos Galante sobre o período em que cursou o ginásio, de 1933 a 1938, destacam a disciplina rigorosa do Ginásio do Estado: os alunos deveriam se levantar quando o professor entrasse em sala de aula e havia bedéis, funcionários que se sentavam num canto para controlar a presença e o comportamento dos estudantes. Os bedéis assistiam a todas as aulas e alguns se instruíam e eventualmente auxiliavam os alunos nos estudos na época de provas. O autor fala dos professores, todos catedráticos, que, além de lecionarem nessa escola, dedicavam-se ao Ensino Superior nas escolas isoladas existentes na capital antes da criação da Universidade de São Paulo. Eram professores exigentes, respeitados e temidos pelos estudantes. 
Muitos docentes, todos homens, são contemplados nas recordações do autor, que discorre sobre eles, suas características e práticas em sala de aula, e, em alguns casos, faz sobressair suas próprias relações, como aluno, com as disciplinas ensinadas por esses professores.

Considerando a carreira profissional do autor, focalizamos, aqui, com mais detalhes, os professores de Matemática. São três docentes: Cândido Gonçalves Gomide, Cruz e Antônio Aguiar. O primeiro é retratado com destaque para "sua capacidade, bondade e pureza de alma" e para seu conhecimento não só de Matemática como de outras disciplinas. Galante registrou, também, as deficiências didáticas desse professor formado na Bélgica como engenheiro eletricista: "faltava-lhe método para expor a matéria, de modo que suas aulas se tornavam difíceis e cansativas" (p. 18). No entanto, o ex-aluno reconhece o esforço desse mestre e sua boa vontade para esclarecer as dúvidas dos estudantes nas aulas, nos intervalos e mesmo em sua própria residência. É notória a admiração de Galante por Gomide, seu colega de trabalho posteriormente, quando ele mesmo lecionava no Ginásio do Estado. Nessa ocasião, o memorialista reafirmou seus sentimentos de apreciação quanto às qualidades de seu antigo professor e, especialmente, quanto às suas atitudes relacionadas ao bem estar e ao sucesso dos estudantes.

\begin{abstract}
Homem de inteligência extraordinária, de coração enorme, humildade e pureza tão acentuadas que afirmo nunca ter conhecido pessoa cujo nome assentasse tão bem como nele: Cândido. Incapaz de perceber a maldade, de alma pura e cristalina, incapaz de negar um favor, mesmo que para isso tivesse de se empenhar. Sofria com o insucesso dos alunos e, na atribuição das notas, procurava ser o mais justo possível. Corrigia as provas escritas com o máximo cuidado e, se por acaso algum pedisse revisão, era por ele atendido. Fazia-a junto com o aluno, mostrava os erros cometidos, somava tudo novamente, numa expectativa ansiosa de encontrar algum engano seu que possibilitasse melhorar a nota. Quando isso não ocorria, ficava angustiado e nervoso por não poder ajudar (GALANTE, 1997, p. 31-32).
\end{abstract}

A segunda figura de professor de Matemática presente na obra é a do professor Cruz, cujo nome completo não é mencionado e que, diferentemente de Gomide, é apresentado como causador de pavor nos alunos devido a seu rigor e exigência. O memorialista sublinha essas características dizendo que esse docente era realmente uma "cruz" pesada carregada pelos estudantes. Sua prática é descrita como a de seguir "ao pé da letra" o livro de Charles Comberousse $^{6}$, tendo o hábito de chamar os estudantes para demonstrar teoremas de geometria no quadro-negro. Como os alunos não tinham, em geral, condições de comprar a obra, precisavam consultá-la na biblioteca da escola. O autor comenta que, devido a essa

\footnotetext{
${ }^{6}$ Charles Comberousse (1826-1897) escreveu diversos manuais para o ensino da Matemática, além de outras obras. Foi professor no Liceu Chaptal, em Paris, de 1854 a 1883. Informações disponíveis no site da Biblioteca Nacional da França: 〈http://data.bnf.fr/11897420/charles_de_comberousse/>. Acesso em: 26 mar. 2016.
} 
necessidade, acostumou-se, desde menino, a estudar em livros franceses. Aluno de Cruz na segunda vez em que cursou a primeira série, relata ter sido o único a conseguir aprovação em primeira época, ainda que com a nota mínima. O rigor desse professor, segundo Galante, espantava muitos alunos, que migravam para escolas particulares. É notável, nas memórias, o contraste estabelecido entre as atuações de Cândido Gomide e Cruz como docentes de Matemática.

O terceiro professor de Matemática focalizado, Antônio Aguiar, lecionou para o leitor no quinto ano e, num único parágrafo, é caracterizado como um jovem entusiasta com talento didático e, embora exigente, capaz de "dar oportunidade para os alunos se recuperarem e superar as dificuldades" (p. 19).

Além dos professores de Matemática, Carlos Galante registrou lembranças de docentes de Latim, Francês, Português, História e Química, referindo-se ao modo como ensinavam nas aulas e, em relação a alguns, manifestando grande admiração pela postura como educadores. Esse é o caso do professor de História, Cesarino Júnior.

Tendo trabalhado no comércio mantido no Brás por seus irmãos durante os seis anos passados no ginásio, com o fechamento do estabelecimento fundado pelo pai devido aos prejuízos no ano de 1938, a situação de Carlos se modificou. Com o ginásio completo, ele podia tentar realizar seu projeto de graduar-se como engenheiro, já que estava habilitado a prestar concurso no Ensino Superior segundo a legislação da época. Contudo, precisava continuar a trabalhar e o fez exercendo um cargo de escriturário na loja da empresa Singer de máquinas de costura localizada no Brás. Posteriormente transferido para a loja de Vila Mariana, matriculou-se num curso preparatório para o ingresso ao Ensino Superior, o PréEngenharia Oswaldo Cruz. Em virtude do trabalho, tinha de, depois do expediente, tomar rapidamente um ônibus para assistir as aulas e de, muitas vezes, como responsável pelo caixa, retornar à loja depois das 23 horas. No dia seguinte, estava de volta ao trabalho pontualmente às 8 horas. Galante acentua os esforços realizados até a conclusão do Pré-Engenharia, em dezembro de 1941, quando se inscreveu no vestibular de Matemática da Universidade de São Paulo e pediu demissão da Singer.

Nas poucas linhas das memórias sobre o curso pré-universitário, os professores são elogiados e o autor destaca que a turma "muito pequena, com pouco mais de meia dúzia de alunos, tornava o aproveitamento bem melhor" (p. 25). O professor de Matemática se chamava João Breves e, segundo Galante, "deu toda a parte de limites, derivadas, funções, álgebra superior e teoria dos conjuntos com uma clareza espetacular” (Idem). A admiração 
por Breves era tão grande que, mais de cinquenta anos depois, seu ex-aluno ainda guardava apontamentos de suas aulas.

Em 1942, o memorialista ingressou na Faculdade de Filosofia da USP, no curso de Bacharelado em Matemática, com duração de três anos. As recordações sobre esse período, encerrado com a formatura, em 1944, em uma turma na qual se graduaram somente oito alunos $^{7}$, figuram no capítulo denominado "Cursando Matemática na USP".

O curso de Matemática da USP foi criado juntamente com a Faculdade de Filosofia, Ciências e Letras e a própria universidade em 1934, e foi o primeiro desses cursos estabelecidos no Brasil. Trabalhos como Silva (2000), Ziccardi (2009) e Cavalari (2012), ao se referirem à subseção de Ciências Matemáticas da Faculdade, responsável pelo curso, assinalam que o corpo docente foi formado a partir da contratação de professores italianos, realizada por Theodoro Ramos (1895-1936). Destacam-se os nomes de Luigi Fantappiè (1901-1956) e Giacomo Albanese (1890-1948). Quando Carlos Galante começou o curso de Matemática, em 1942, os professores eram ex-alunos desses docentes. Ele enumera alguns de seus nomes - Omar Catunda, Benedito Castrucci, Edison Farah, Fernando Furquim de Almeida $^{8}-$, mas não trata desses docentes individualmente.

Assim, as memórias não trazem testemunhos quanto ao modo como os professores de Matemática atuavam individualmente no dia a dia da sala de aula do curso universitário do autor. Entretanto, Galante empreende uma descrição bastante viva do alto grau de exigência das avaliações praticadas pelos mestres para ressaltar as enormes dificuldades a serem transpostas pelos estudantes.

\begin{abstract}
O curso era duríssimo, com um grau de exigência acima do normal. Tínhamos provas semestrais e a final em dezembro. Provas escritas e orais, em que não havia relação de matéria para elas: o exame versava sobre tudo que havia sido dado durante o ano. Como a classe fosse pequena, o professor marcava com cada aluno ou grupo de alunos o dia e hora da prova oral. Um aluno chegava a ser arguido durante quase hora e meia e, caso errasse algum assunto tido como fundamental, estaria reprovado, sem qualquer possibilidade de reclamação. Um verdadeiro suplício, tanto que chamávamos esses exames orais de "tribunal de inquisição". Submetiam-se a eles os que obtivessem média entre 5 e 7; para aqueles com média entre 3 e 5 havia o exame de segunda
\end{abstract}

\footnotetext{
${ }^{7} \mathrm{O}$ convite de formatura dos bacharelandos nos diversos cursos da Faculdade no ano de 1944, reproduzido à página 28 do livro, mostra que apenas oito alunos se graduaram em Matemática. Além do autor, figuram os seguintes estudantes: Antonio de Souza Teixeira Júnior, Eunice P. de C. Silva, Jenny Chedid, Luiz Mauro Rocha, Marina Moniz Rebouças, Oswaldo Marcondes dos Santos e Palmyra A. Sampaio.

${ }^{8}$ Segundo Silva (2000), Fantappiè esteve no Brasil de 1934 até 1939 e Albanese, que veio a convite do primeiro, chegou em 1936 e viveu em São Paulo o resto de sua vida. Fantappiè foi contratado para a disciplina de Análise Matemática e Albanese foi encarregado das disciplinas de Geometria. Omar Catunda (1906-1986) graduou-se em Engenharia na Escola Politécnica em 1933, antes da fundação da USP (POSSANI, 2015). Edison Farah (1915-2006) bacharelou-se na primeira turma do curso de Matemática da USP em 1936 (FARAH; ALAS; ABUD, 2015), assim como Fernando Furquim de Almeida (1913-1981) (SILVA, 2000). Benedito Castrucci (1909-1995) formou-se em dois cursos da mesma universidade: Direito, em 1935, e Matemática, em 1939 (BARCO, 2015).
} 
época em fevereiro, com rigor redobrado e, finalmente, a dependência. Se o aluno fosse reprovado duas vezes numa mesma disciplina, estava automaticamente jubilado. Assim, vários não puderam concluir o curso, mesmo, quando, em alguns casos, tivessem conseguido chegar ao $2^{\circ}$ ano (GALANTE, 1997, p. 27).

Galante usa termos como "massacre" e "degola" para caracterizar os estudos e exames, cujas dificuldades eram aumentadas por outros fatores como a pequena disponibilidade de livros, por todos serem estrangeiros e de difícil aquisição devido ao período de guerra. O autor enfatiza as sessões de estudo com os colegas Oswaldo Marcondes e Luiz Mauro Rocha, arduamente desenvolvidas à noite, nos fins de semana e nos feriados. Destaca mais uma vez os esforços que despendeu porque, além de estudar intensamente, teve que lecionar para sobreviver enquanto fazia o curso de Matemática que o habilitaria a ser professor secundário.

Após os três anos que formavam o bacharel em Matemática, os que pretendiam ser professores cursavam a licenciatura, que constava de um ano de "matérias pedagógicas", ministradas na Escola Caetano de Campos. Esse curso reunia estudantes de todos os departamentos e, de acordo com Galante, era composto “de Psicologia, Didática, Ciências Sociais, Pedagogia e Prática de Ensino” (p. 29). Galante contrapõe essa parte de sua formação ao caráter árduo dos três anos anteriores: "Como havíamos feito um curso duríssimo, o estudo dessas matérias foi ameno, não exigindo qualquer esforço ou preocupação. Às vésperas das provas, bastava ler o resumo das aulas para realizar um bom exame" (Idem).

\section{0 professor de Matemática Carlos Galante}

Ainda como estudante da USP, Carlos Galante começou a lecionar no Ginásio do Estado, onde havia realizado seu curso secundário, tendo, então reencontrado alguns de seus antigos mestres. Ele narra sua passagem por uma série de escolas de Ensino Secundário e Superior ao longo de sua carreira e procura se retratar como um professor paciente e preocupado com o sucesso de seus alunos. Referindo-se, por exemplo, a seu trabalho com as primeiras séries do Ginásio do Estado, diz que gostava dessas classes por seu entusiasmo e capacidade de aprender e assim descreve seus procedimentos em relação a elas:

Com elas obtive resultados ótimos, pois buscava sempre incentivá-las, mostrando o quanto eram capazes de realizar. Se alguém tivesse dificuldade ou tirasse nota baixa, interessava-me em saber a razão do fracasso. Sentindo interesse do professor, os alunos esforçavam-se em não decepcioná-lo. Eu procurava ser o mais didata possível, empenhando-me para que tirassem o melhor proveito das aulas. Exigente sem ser intolerante. Sentia ser bem aceito pelos alunos e mantínhamos um bom relacionamento. Procurava tornar a aula agradável e gostosa para amenizar a exigência da matéria (GALANTE, 1997, p. 31). 
Nota-se que o autor, ao escrever suas memórias, fez questão de mostrar que seus esforços como professor foram reconhecidos por muitos de seus alunos, que lhe manifestaram gratidão e admiração em diversas ocasiões ao longo do tempo. Muitos episódios relativos a esse tema habitam o livro, especialmente no capítulo denominado "Emoções que vivi", que se inicia com um trecho em que Galante assinala a presença de situações que lhe deixaram impressões significativas quanto à carreira docente e revela tê-las salvo materialmente ou na memória:

Após tantos anos de magistério, a vida de professor é rica em lembranças e emoções. Existem momentos marcantes que jamais esquecemos. Tudo o que foi possível registrar guardei em meu baú de recordações, outros fatos estão em minha memória (GALANTE, 1997, p. 99).

Os encontros com antigos alunos, em que sempre ouviu palavras de reconhecimento, são qualificados como gratificantes. Mesmo um aluno reprovado por ele the contou que o incentivo do professor o havia feito estudar com afinco e passar a gostar de Matemática, a ponto de ter se tornado professor da disciplina, descobrindo "sua verdadeira vocação" (p. 100).

Um aspecto interessante das memórias docentes de Galante está na narração de sua participação em atividades socioculturais desenvolvidas fora de sala de aula pelos estudantes e no relato de algumas práticas nem sempre usuais, como a elaboração de um "Caderno Dirigido" pelas classes para as quais lecionava, inspirada diretamente pelo professor Malba Tahan ${ }^{9}$. Vejamos como o autor narra seu encontro com ele.

O Instituto de Educação Américo Brasiliense (IEAB), de Santo André, foi a escola estadual na qual o memorialista atuou desde 1957 até sua aposentadoria. Nas festividades de inauguração do novo prédio dessa escola, em 1962, Malba Tahan, que residia no Rio de Janeiro, proferiu palestras a convite de Galante. Segundo Galante, essas palestras atraíram não somente os estudantes, mas um público amplo da cidade, que se deliciou "com a matemática divertida e interessante mostrada" (p. 54). O "Caderno Dirigido" lhe foi sugerido pelo visitante e era um caderno produzido pelos estudantes na forma de um livro, com folha de guarda, folha de rosto, dedicatória, prefácio etc. Galante relata ter orientado os alunos do $2^{\circ}$ ano científico nessa atividade. De acordo com o autor, os cadernos eram organizados de maneira uniforme por todos os estudantes e, além de registros referentes a questões de Matemática, continham escritos dos alunos em alusão a aniversários de colegas e a festas como o Dia das Mães, bem como "pensamentos famosos ou sonetos de grande valor literário"

\footnotetext{
${ }^{9}$ Como é bem conhecido, Malba Tahan foi o pseudônimo adotado pelo escritor e professor de Matemática paulista Júlio César de Melo e Souza (1895-1974), que se celebrizou pelas ações de divulgação da Matemática e pelas propostas de ensinar essa disciplina de maneira completamente inovadora.
} 
(p. 54), esses últimos selecionados pelo professor. O caderno motivava a realização de uma celebração quando se chegava ao centésimo exercício, porque o professor conclamava uma turma a preparar um show ou peça teatral para a comemoração referente a outra classe. Nessa festa, havia um bolo com velas, decorado com fórmulas matemáticas, e a entrega de brindes aos alunos que "respondessem corretamente a questões referentes à matéria constante do caderno" (GALANTE, 1997, p. 54).

O IEAB é retratado como a instituição escolar de maior significado na vida do autor, que guardou dela lembranças muito belas, por sua "convivência com os alunos não apenas na sala de aula, mas também sentindo toda sua criatividade e espontaneidade em atividades extracurriculares" (p. 57-58). Um registro especial é feito por Galante em relação a um aspecto de sua atuação no curso normal desse instituto: trata-se de um estudo que desenvolveu com as alunas desse curso sobre os problemas de aritmética, "um tormento para os alunos" (p. 118) que faziam o Exame de Admissão e muito frequentemente eram reprovados devido às dificuldades em resolver esses problemas.

O Exame de Admissão ${ }^{10}$, instituído em 1931, a partir da Reforma Francisco Campos, constituía a forma de ingresso no Ensino Secundário, organizado nacionalmente, depois dessa reforma, em dois ciclos: curso ginasial, com cinco anos de duração, e curso complementar, de dois anos, necessário para a entrada no Ensino Superior e geralmente realizado em salas anexas às escolas que o ofereciam (ABREU; MINHOTO, 2012). Galante comenta com entusiasmo a "Visualização de Problemas de Aritmética", seu método desenvolvido com as normalistas para a abordagem dos problemas, que consistia na tradução do problema num desenho esquematizado.

Realmente a ilustração adequada cumpre dupla finalidade: permite entender facilmente o raciocínio adotado e elimina a aridez do problema, pois o desenho, sendo uma linguagem universal, é compreendida por todos e, de modo especial, pelas crianças. $\mathrm{O}$ aluno passa a entender o porquê das operações efetuadas e, facilmente, torna-se capaz de resolver outro problema. (...)

É o meio mais correto de respeitar a evolução psicológica da criança, cujo espírito passa de uma mentalidade concreta a uma mentalidade abstrata, ao fazer sistematicamente apelo à visualização, ou seja, dando representações concretas para idéias abstratas (GALANTE, 1997, p. 119).

\footnotetext{
${ }^{10}$ Além de ter pelo menos 11 anos de idade, o candidato ao primeiro ano do ginásio, segundo a legislação, deveria ser aprovado no Exame com classificação suficiente, e era necessário, para ele, apresentar um requerimento e pagar uma taxa. O Exame só poderia ser prestado em uma escola, aquela em que o candidato pretendesse se matricular, e era constituído por provas escritas de Português e Aritmética, e provas orais dessas mesmas disciplinas e de Geografia, História do Brasil e Ciências Naturais. O Exame era um ritual de passagem entre os estudos primários e secundários e seus programas e regras eram determinados pelo Departamento Nacional de Ensino (ABREU, MINHOTO, 2012).
} 
Exemplos da resolução dos problemas com o uso de desenhos (feitos por normalistas) foram incorporados ao livro didático de Galante para a primeira série do ginásio e são apresentados no capítulo intitulado "Como perder o medo da Matemática". Como comentamos no início deste texto, essa mesma denominação faz parte do subtítulo do livro de memórias. A existência de temores dos estudantes quanto à Matemática é discutida detalhadamente pelo autor, que reitera sua fé na capacidade de aprendizagem de todos, desde que exista dedicação. Galante insiste em que o ensino seja adequado, criticando severamente as atitudes de professores despreparados, responsáveis por traumas nos alunos em relação à disciplina: "Não sabem incentivá-los a superar as dificuldades, passam a ideia de ser exclusiva de cérebros privilegiados, o que é uma grande mentira. A Matemática do Curso Secundário é acessível a qualquer aluno normal e todos necessitam de seu conhecimento, para prosseguirem os estudos" (p. 117).

No capítulo "Ser Professor", o memorialista enumera os três elementos básicos para o sucesso de um professor: "conquistar a classe pela simpatia e confiança", "estimular os alunos" e "dominar a matéria para ser respeitado; ser ordenado e planejado, procurando destacar do conteúdo as partes mais importantes" (p. 111-112). Ele vê o ensino como uma arte a que o docente deve se entregar com amor e dedicação, um trabalho "que não se resume em transmitir conhecimentos ou habilidades, porém em educar, o que envolve certa atmosfera afetiva, exigindo do mestre os melhores dotes de compreensão e comunicação humana" (p. 113). Para Carlos Galante, sendo idealista, compreensivo, capaz de marcar e formar personalidades, o professor marcará para sempre o coração de seus alunos e "os benefícios que conseguiu proporcionar jamais de apagarão". Por essa razão, de acordo com o autor, "não há nada mais gratificante do que ser professor, principalmente quando nos é dado ver o resultado de nosso trabalho, de nosso esforço e de nossa dedicação" (p. 114).

\section{Comentários finais}

Retomemos, agora, alguns aspectos das memórias de Carlos Galante na perspectiva dos parâmetros teórico-metodológicos que nos orientam. Podemos, então, procurar analisar as intenções do autor ao escrever suas memórias e refletir sobre suas escolhas para isso. Ele próprio nos diz, no Prefácio (p. 9), que desejou "assinalar a experiência acumulada ao longo de quase cinquenta anos de magistério" e registrar a marca deixada por alguns de seus antigos professores, "que merecem ser lembrados por seu comportamento, atitude e honestidade". No retrato dos mestres que o autor nos apresenta, é nítida sua admiração especial por Cândido 
Gomide, cuja bondade e preocupação com o bem-estar e o sucesso dos alunos são muito salientados. Essa imagem positiva é contrastada com a de outro professor de Matemática, que se destacava negativamente pela atitude oposta de rigidez e extrema exigência, provocadora do pavor dos alunos, que, por isso, muitas vezes, se transferiam para outra escola.

Ao elencar as qualidades do bom professor, Galante enfatiza a paciência, a compreensão, a afetividade, o carinho e a preocupação com a aprendizagem dos alunos, o que sinaliza lições aprendidas por ele com seus professores e particularmente com Gomide. No momento de rememorar e escrever sobre sua vida de professor, o autor usa um tom contundente para afirmar que professores atenciosos, compreensivos, humanos transmitem segurança e confiança aos alunos, que respondem positivamente a seus esforços e os reconhecem. Simultaneamente, o memorialista tece críticas incisivas em relação àqueles que aterrorizam os alunos com as dificuldades da Matemática, asseverando que a aprendizagem é possível desde que haja investimentos tanto dos professores quanto dos alunos. Acreditamos, então, que a convivência do autor com os professores retratados teve repercussões na formação do futuro professor de Matemática Carlos Galante.

No texto introdutório do livro, Galante afirmou que não considerava extraordinária sua vida, mas acreditava que ela teve passagens interessantes, sobretudo devido a sua origem humilde. Na leitura das memórias, constatamos a presença de frequentes menções aos esforços que o autor realizou para se tornar o que foi, principalmente do ponto de vista profissional: professor, engenheiro e autor de livros didáticos de sucesso. Galante realça, como vimos, que seus pais e irmãos não tiveram oportunidade de estudar e que ele mesmo, para realizar dois cursos superiores numa época em que somente uma pequena parcela da população brasileira fazia estudos além da escola primária, teve a necessidade de trabalhar simultaneamente aos estudos.

Outro ponto interessante é que o autor publicou um livro ricamente documentado, o que nos indica que talvez sua intenção, ao guardar tantos papéis, não fosse somente compor um arquivo de sua vida, mas também aproveitá-los para escrever memórias. O texto da orelha da obra dá indícios de que a oportunidade de publicá-las está ligada ao grande sucesso do autor de livros didáticos de Matemática na Editora do Brasil. De fato, afirma-se que a publicação da obra foi uma exceção aberta por uma editora especializada em livros didáticos e paradidáticos visando homenagear um mestre e, junto a ele, milhões de professores.

A leitura desse livro evidencia que Carlos Galante realizou um balanço extremamente positivo de sua vida toda e, especialmente, de sua vida como professor de Matemática. Cabe refletir que, ao inventariar o passado e procurar dar sentido aos acontecimentos de sua vida 
julgados significativos, o memorialista optou por iluminar episódios particulares que lhe deram satisfação no momento em que os evocou para compor as memórias. O tom dominante da narrativa é o do sucesso, alcançado principalmente pelo esforço do personagem. Nota-se, portanto, que, na triagem das lembranças, o autor preferiu não escolher ou não insistir nos aspectos sombrios que fazem parte de qualquer vida humana.

As lembranças de alunos e professores construídas em livros como o focalizado oferecem, no caso da obra aqui estudada e de outras, materiais indispensáveis para a compreensão da história da formação e atuação de professores de Matemática no Brasil. Considerá-los envolve, porém, saber que um discurso de apresentação de si como o proferido pelos que escrevem memórias é uma narrativa de identidade que se apresenta como uma ilusão biográfica criada pela transformação de "um passado feito de rupturas e descontinuidades em um traçado que religa o que estava separado" (CANDAU, 2014, p. 72). Em função do presente, esse ato de memória organiza os traços da memória deixados pelo passado e os torna coerentes para estabelecer uma imagem satisfatória do rememorador. No livro aqui contemplado, ao empreender esse trabalho, Carlos Galante produziu uma fonte relevante para a compreensão de algumas dimensões históricas da formação de um professor de Matemática no Brasil do século XX.

\section{Referências}

ABREU, G. S. A. de.; MINHOTO, M. A. P. Política de admissão ao ginásio (1931-1945): conteúdos e forma revelam segmentação do primário. Campinas, Revista HISTEDBR, On-line, n. 46, p. 107-118, 2012.

BARCO, L. Professor Doutor Benedito Castrucci: um paradigma da Educação Matemática. In: MAGALHÃES, L. E. de. (Coord.). Humanistas e cientistas do Brasil: Ciências Exatas. São Paulo: Editora da Universidade de São Paulo, 2015. p. 41-52.

BASTOS, M. H. C. Reminiscências de um tempo escolar. Memórias do Professor Coruja. Educação em Questão, Natal, n. 25, p.157-189, 2006.

BRAGHINI, K. M. Z. A Editora do Brasil S/A nos anos 1960-1970: a consolidação de uma editora brasileira no mercado didático e o ensino de educação moral e cívica. Revista Brasileira de História da Educação, Maringá, v. 12, n. 3 (30), p. 153-178, 2012.

BRITO, A. de J.; OLIVEIRA, A. G. Desfiar e fiar a Aritmética da Boneca Emília: práticas no ensino de matemática na obra de Monteiro Lobato. Zetetiké, Campinas, v. 23, n. 43, p. 95-132, 2015.

BÚRIGO, E. Z. Marcel Proust e as reminiscências de um mau aluno. Zetetiké, Campinas, v. 23, n. 43, p.133-154, 2015.

BOURDIEU, P. A ilusão biográfica. In: AMADO, J.; FERREIRA, M. de M. (Coord.). Usos \& abusos da história oral. Rio de Janeiro: Editora FGV, 2006. p. 183-191. 
CAVALARI, M. F. Um histórico do curso de Matemática da Faculdade de Filosofia, Ciências e Letras (FFCL) da Universidade de São Paulo (USP). Revista Brasileira de História da Matemática, Rio Claro, v. 12, n. 25, p. 15-30, 2012.

CANDAU, J. Memória e identidade. 1. ed., 2ª reimpressão. São Paulo: Contexto, 2014.

CUNHA, M. T. S. Essa coisa de guardar... Homens de letras e acervos pessoais. História da Educação, Pelotas, v.12, n. 25, p. 109-130, 2008.

FARAH, F.; ALAS, T. O.; ABUD, Z. I. Professor Doutor Edison Farah. In: MAGALHÃES, L. E. de. (Coord.). Humanistas e cientistas do Brasil: Ciências Exatas. São Paulo: Editora da Universidade de São Paulo, 2015. p. 65-80.

GALANTE, C. Memórias. 1. ed. São Paulo: Editora do Brasil, 1997.

GALVÃO, A. M. de O. Amansando meninos: uma leitura do cotidiano da escola a partir da obra de José Lins do Rego. 1. ed. João Pessoa: Editora Universitária/UFPB, 1998.

GARNICA, A. V. M (Org.). Cartografias Contemporâneas: Mapeando a Formação de Professores de Matemática no Brasil. 1. ed. Curitiba: Appris, 2014.

GOMES, A. C. Escrita de si, escrita da História: a título de prólogo. In: GOMES, Angela de Castro. (Org.). Escrita de si, escrita da história. Rio de Janeiro: Editora da FGV, 2004. p. 7-24.

GOMES, M. L. M. Potencialidades da literatura como fonte para a História da Educação Matemática: a obra de Pedro Nava. Bolema, Rio Claro, n. 21, p. 89-110, 2008.

LACERDA, L. de. Álbum de leitura: memórias de vida, histórias de leitoras. 1. ed. São Paulo: Editora UNESP, 2003.

LARROSA, J. Notas sobre narrativa e identidad (A modo de presentación). In: ABRAHÃO, M. H. M. B. (Org.). A aventura (auto)biográfica: teoria e empiria. Porto Alegre: EDIPUCRS, 2004. p. 11-22.

MARTINS, G. Graciliano Ramos de Oliveira e a sombra da infância. Revista Teias, Rio de Janeiro, v. 14, n. 31, p. 20-33, 2013.

MARTINS-SALANDIM, M. E. A interiorização dos cursos de Matemática no estado de São Paulo: um exame da década de 1960. 2012. 379 f. Tese (Doutorado em Educação Matemática) Instituto de Geociências e Ciências Exatas, Universidade Estadual Paulista, Rio Claro, 2012.

MELO, J. F. Modos e condições de participação na cultura do escrito: Pedro Nava e a formação na família (1903-1913). 2008. 243 f. Dissertação (Mestrado em Educação) - Faculdade de Educação, Universidade Federal de Minas Gerais, 2008.

MIGUEL, A. O que dizem os estudos já elaborados sobre a emergência da história da educação matemática no Brasil? In: VALENTE, W. R. História da educação matemática o Brasil:

problemática de pesquisa, fontes, referências teórico-metodológicas e histórias elaboradas. São Paulo: Livraria Editora da Física, 2014. p. 30-45.

NEVES, S. A.; GALVÃO, A. M. de O. Representações da infância em memórias e autobiografias Minas Gerais (1900-1960). História da Educação, Pelotas, v. 20, n. 48, p. 235-257, 2016.

PERES, E.; BORGES, F. Relações entre história e literatura: a obra de Cora Coralina e as questões do ensino e dos processos de escolarização no final do século XIX e início do século XX. Revista

Brasileira de História da Educação, Maringá, v. 15, n. 2 (38), p. 23-53, 2015. 
POSSANI, C. Omar Catunda. In: MAGALHÃES, L. E. de (Coord.). Humanistas e cientistas do Brasil: Ciências Exatas. São Paulo: Editora da Universidade de São Paulo, 2015. p. 139-152.

RICOEUR, P. Tempo e narrativa. v. 1. A intriga e a narrativa histórica. 1. ed. São Paulo: WMF Martins Fontes, 2010.

SILVA, C.M.S da. A Faculdade de Filosofia, Ciências e Letras da USP e a formação de professores de Matemática. In: REUNIÃO ANUAL DA ANPED, 23., 2000, Caxambu. Anais... Caxambu: Editora da ANPED, 2000. p. 1-19. Disponível em: 〈http://23reuniao.anped.o rg.br/textos/1925p poster.PDF>. Acesso em: 4 jun 2017.

SOUSA, C. P. de. História, literatura e memórias de formação escolar. História da Educação, Pelotas, n. 17, p. 157-181, 2005.

VIÑAO, A. Las autobiografías, memorias y diarios como fuente histórico-educativa: tipología y usos. Teias: Revista da Faculdade de Educação da UERJ, Rio de Janeiro, n. 1, p. 82-97, 2000.

VIÑAO, A. Relatos e relações autobiográficas de professores e mestres. In: MENEZES, M. C. Educação, memória, história: possibilidades, leituras. Campinas: Mercado de Letras, 2004. p. 333373.

ZICCARDI, L. R. N. O curso de Matemática da Pontifícia Universidade Católica de São Paulo: uma história de sua construção/desenvolvimento/legitimação. 2009. 408f. Tese (Doutorado em Educação Matemática) - Pontifícia Universidade Católica de São Paulo, São Paulo, 2009.

ZILBERMAN, R. Literatura e história da educação: representações do professor na ficção brasileira. História da Educação, Pelotas, n. 15, p. 73-87, 2004.

Submetido em 08 de Junho de 2017. Aprovado em 06 de Novembro de 2017. 